\title{
TEM Analysis of Diffusion-Bonded Silicon Carbide Ceramics Joined Using Metallic Interlayers
}

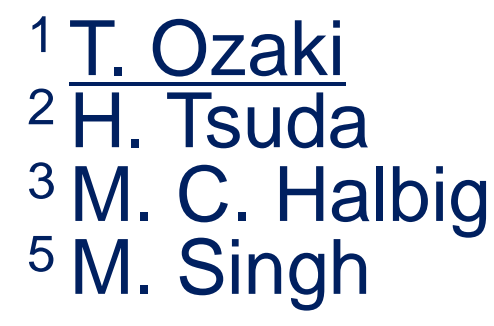

1 Y. Hasegawa

2S. Mori

${ }^{4}$ R. Asthana

1Technology Research Institute of Osaka Prefecture, Osaka, Japan 2Osaka Prefecture University, Osaka, Japan 3NASA Glenn Research Center, Cleveland, Ohio, USA 4University of Wisconsin-Stout, Menomonie, WI, USA ${ }^{5}$ Ohio Aerospace Institute, Cleveland, Ohio, USA

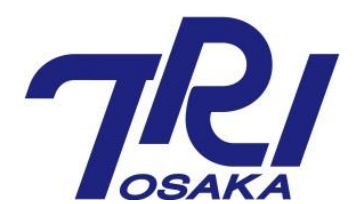

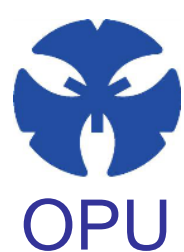

NISA

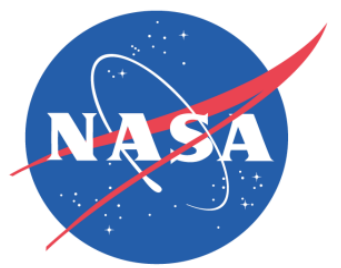

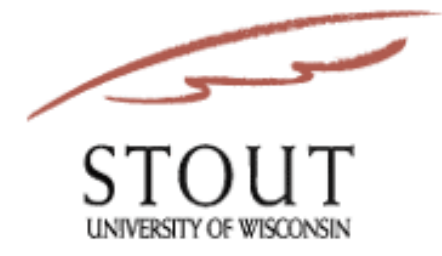




\section{outline}

1. Introduction

properties and applications of SiC (SA-THX)

purpose of diffusion bonding

2. Sample preparations used for diffusion bonding

Substrates : SA-Tyrannohex TM (SA-THX)

Interlayers : Ti-Mo, Ti-Cu foil

3. Experimental results

STEM images of the bonding area

TEM images and SAED patterns of the reaction compound

4. Discussion about the microstructure of the formed phases by diffusion bonding

5. Summary 


\section{SiC fiber-bonded ceramics, SA-Tyrannohex ${ }^{\circledR}$}

\section{SiC composite material}

1. Excellent mechanical properties

2. Good oxidation resistance

3. High thermal stability

\section{Especially,}

\section{SA-Tyrannohex (SA-THX)}

... SiC fiber-bonded ceramics

- High strength sustained up to $1600^{\circ} \mathrm{C}$ in air

- High fracture toughness $\left(1200 \mathrm{~J} \cdot \mathrm{m}^{-2}\right)$

$\Rightarrow$ Promising material for high-temperature and extreme environment applications

e.g. injector applications, combustion liner, nuclear fusion reactor and turbine engine applications

T. Ishikawa et al, Science, 282, 1295-1297 (1998). T. Ishikawa et al, Nature, 391, 773-775 (1998).

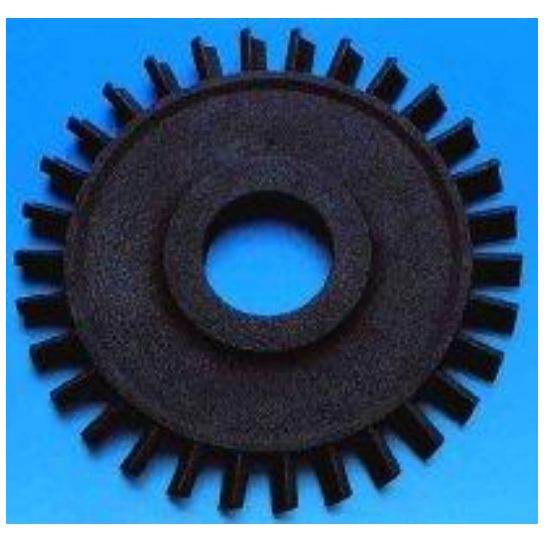

http://www.ube-ind.co.jp/japanese /products/chemical/chemical_19.htm
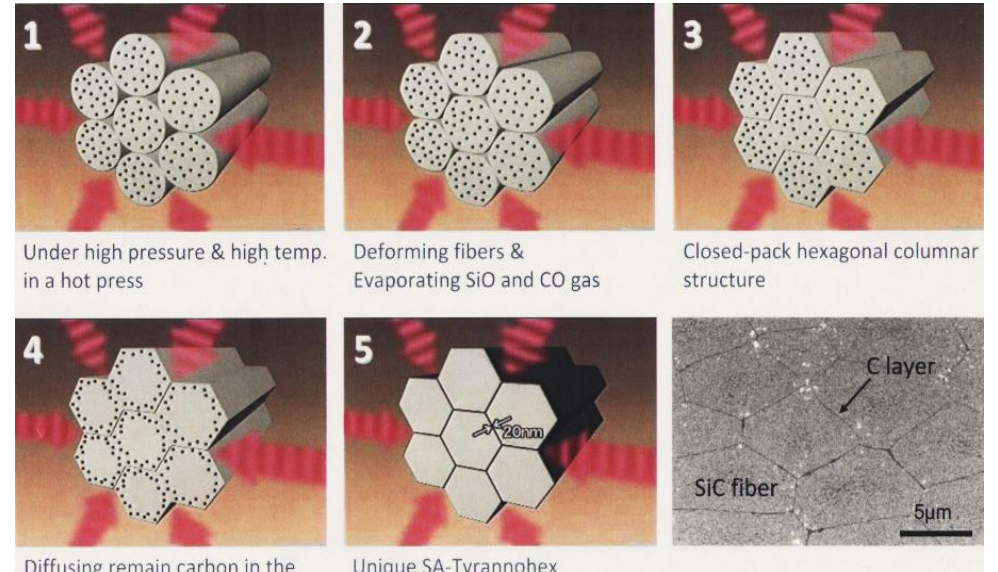

Diffusing remain carbon in the Unique $S A-T Y$
structure structure 


\section{For wide range uses of SA-THX}

However, geometrical limitations hinder the wide use of SA-THX. It is difficult to fabricate large, or complex shaped components by Hot Pressing or CVD.

Therefore, new advanced methods are needed.
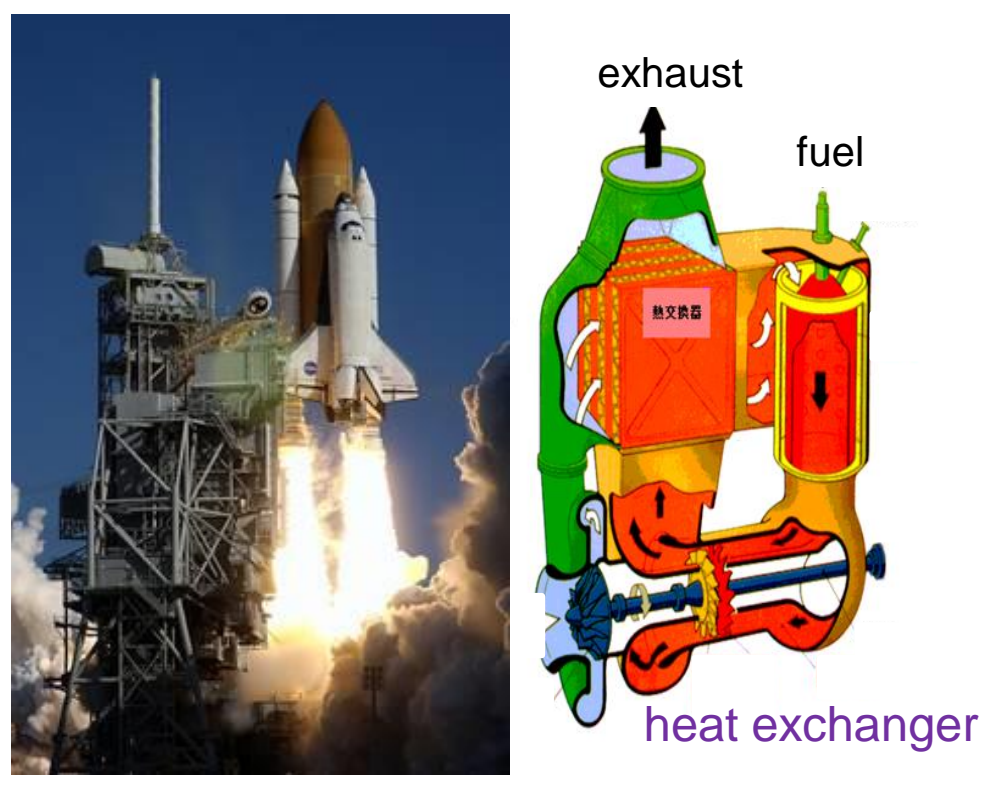

\section{Under those circumstances,}

One cost-effective solution for fabricating large, complex-shaped components is the joining of simple shaped ceramics.

\section{In this study, we are going to focus on diffusion bonding.}




\section{Diffusion Bonding of SA-THX using metallic Interlayers}

\section{Used sample}

@NASA

substrate: SA-THX ...SiC fiber-bonded ceramics, UBE Industries

metallic interlayer: Ti-foil, Mo-foil and Cu-foil, Goodfellow Corporation

Bonding process

Hot-press in $1200^{\circ} \mathrm{C}$, 4hour, vacuum $30 \mathrm{MPa}$

\section{Ti-Mo foil}

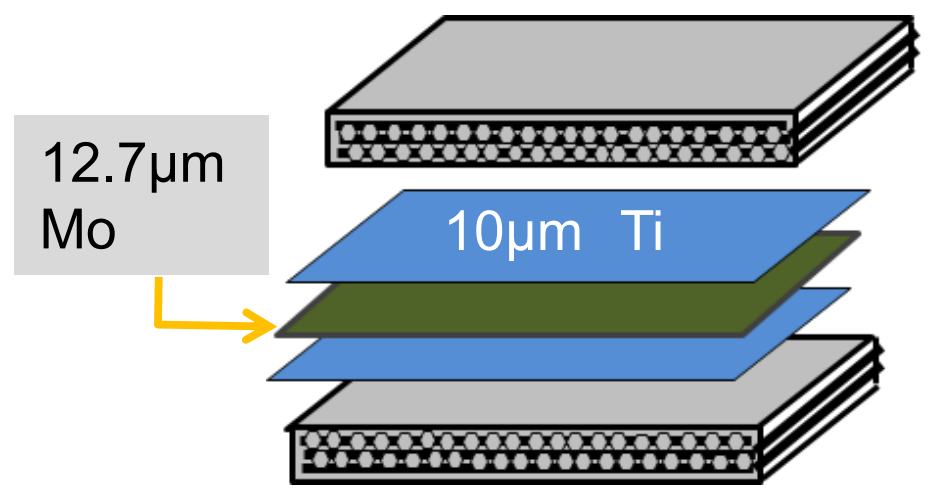

$10 \mu \mathrm{m} \mathrm{Ti}$ and $12.7 \mu \mathrm{m}$ Mo interlayer

\section{Ti-Cu foil}

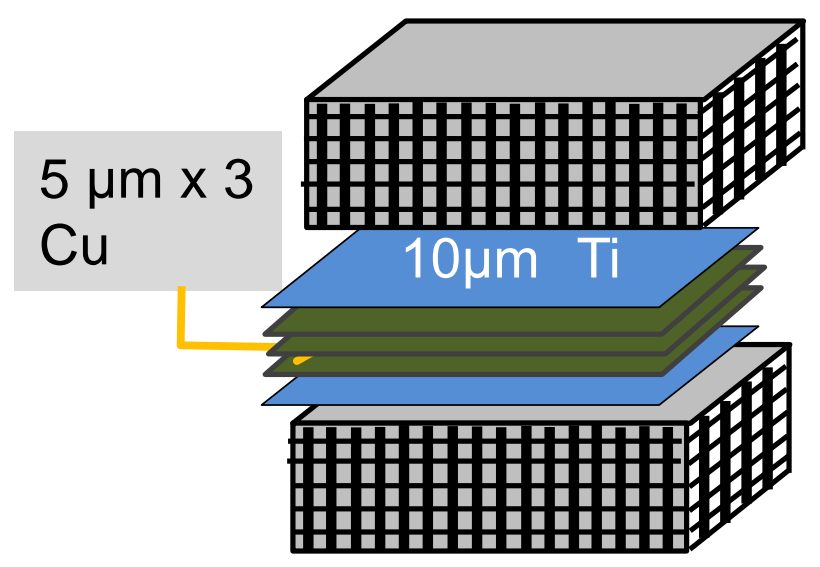

$10 \mu \mathrm{m} \mathrm{Ti}$ and $15 \mu \mathrm{m}$ Cu interlayer

M.C. Halbig, et. al., Ceramics International41(2015)2140-2149 


\section{Diffusion Bonding of a SA-THX using metallic Interlayers}
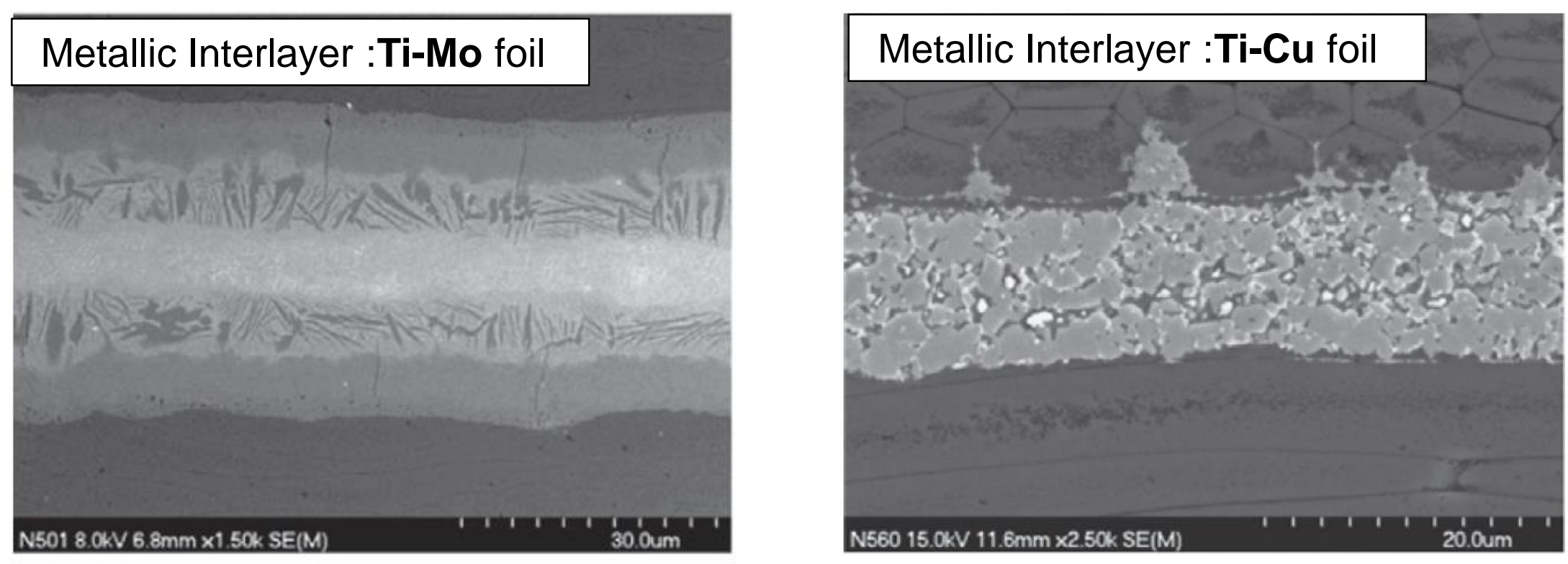

Knoop hardness of diffusion bonded joints.

\begin{tabular}{|c|c|c|}
\hline & Average HK (\| joint) & Average HK $(\perp$ joint $)$ \\
\hline $\begin{array}{l}\text { SA-THX/Ti/Mo/Ti/SA- } \\
\text { THX }\end{array}$ & $717.7 \pm 273.6$ & $758.9 \pm 299.3$ \\
\hline SA-THX/Ti/Cu/Ti/SA-THX & $816.5+43.9$ & - \\
\hline SA-THX (un-bonded) & $1244 \pm 176$ & $624 \pm 205$ \\
\hline
\end{tabular}

M.C. Halbig, et. al., Ceramics International41(2015)2140-2149 


\section{Objectives}

We diffusion bonded $\mathrm{SiC}$ and $\mathrm{SiC}$ ( $\underline{\underline{\mathrm{SA}}-\mathrm{THX} \text { and SA-THX) }}$ using Ti/Cu foil metallic interlayer.

We carried out TEM and STEM observations with the diffusion bonded sample prepared by FIB technique.

1. Evaluate microstructures of the diffusion bonding area by TEM and STEM.

2. Characterize the reaction compound in the diffusion bonding area by STEM-EDS and SAED analysis. 


\section{Experiment ( FIB and STEM )}

Focused Ion Beam, FIB (Hitachi FB-2200)

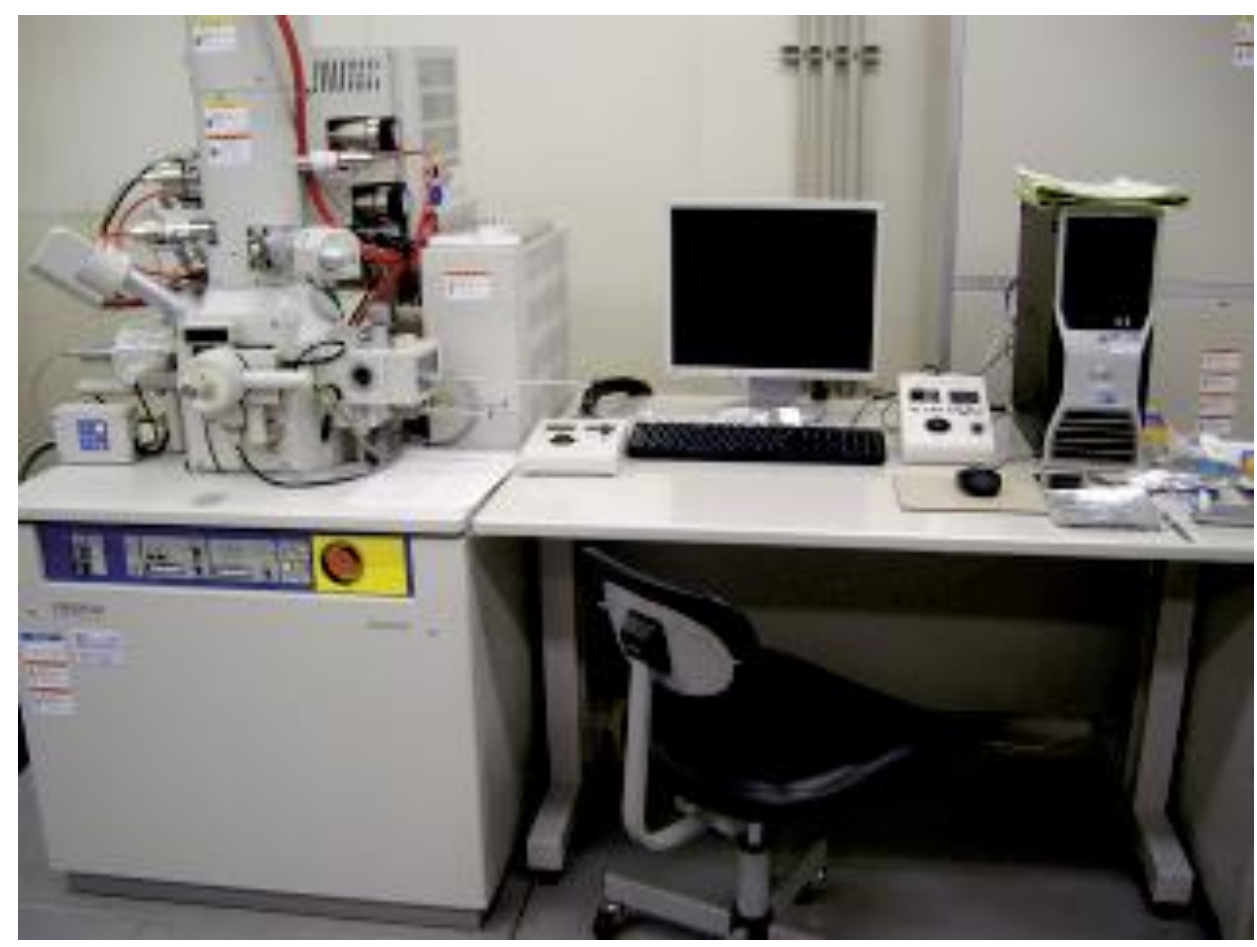

Prepared thin samples for TEM and STEM.

T Re: 産技研 Let's Try with TRI!
Cs-corrected STEM

(Hitachi HD-2700)

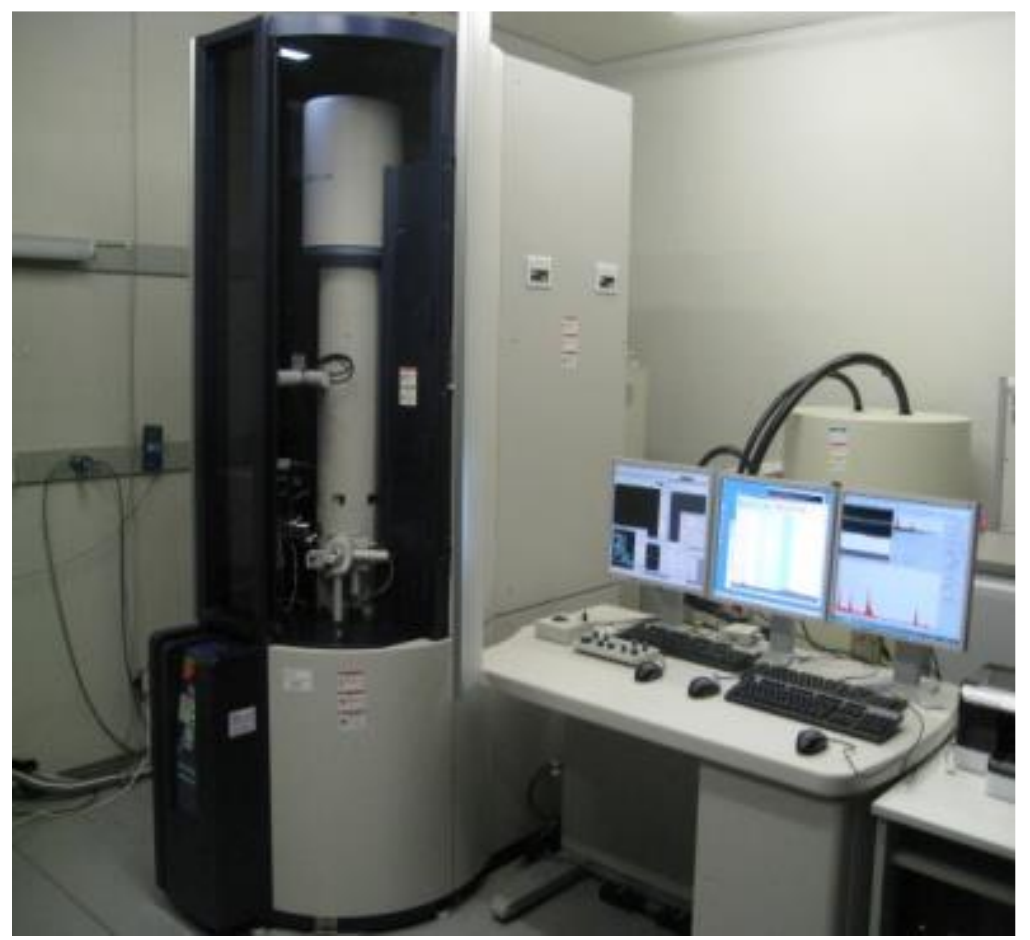

Checked the thin samples prepared by FIB.

Three-Observation mode:

SEM, BF-STEM and HAADF 
Fabricating procedure of the thin sample (SIM image obtained by FIE
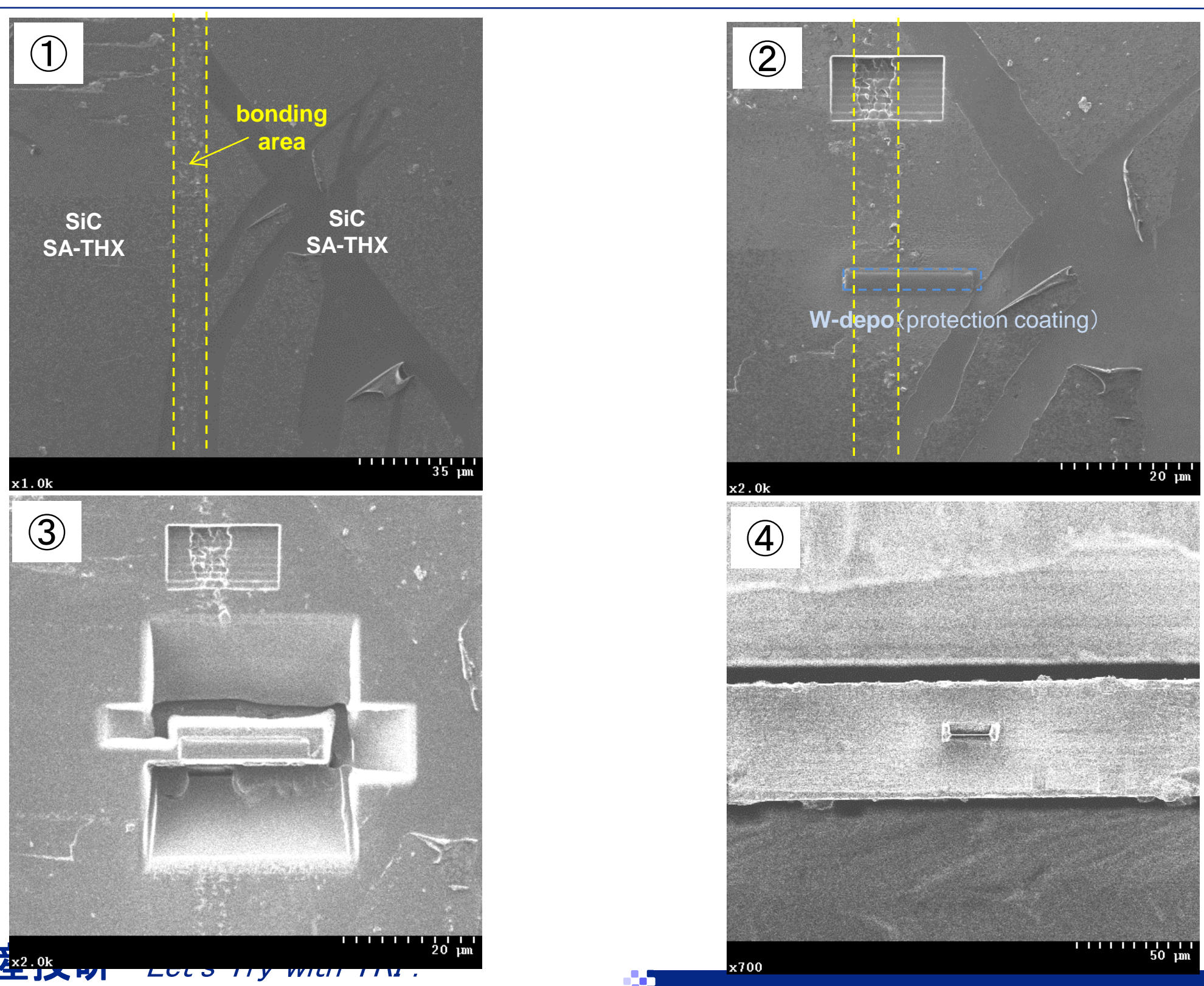

(4)

$(3-1)$ 


\section{STEM observation of the FIB sample}

$\mathrm{Ti} / \mathrm{Cu}$ interlayer parallel to $\mathrm{SiC}$ fiber
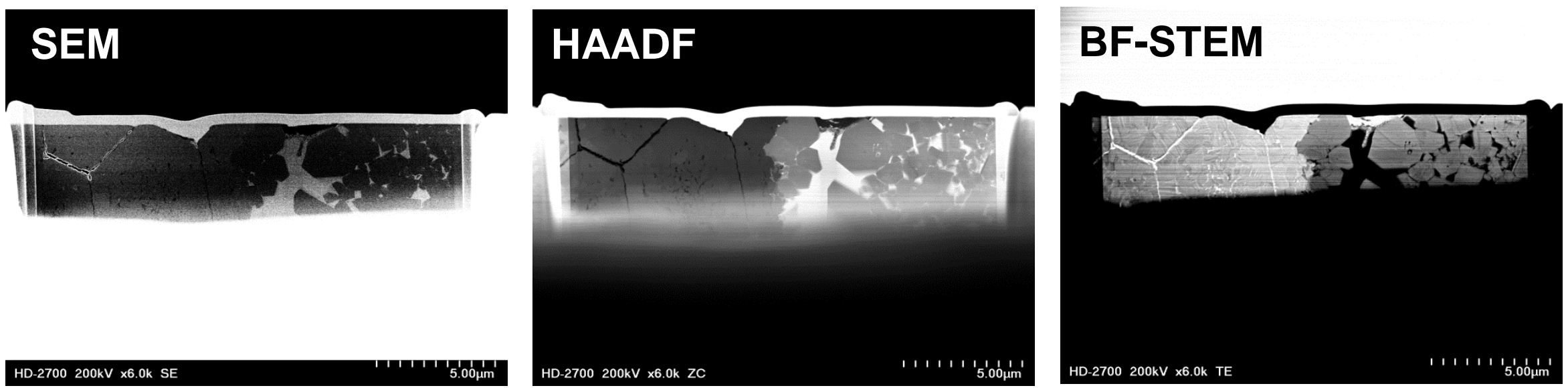

$\mathrm{Ti} / \mathrm{Cu}$ interlayer Perpendicular to $\mathrm{SiC}$ fiber

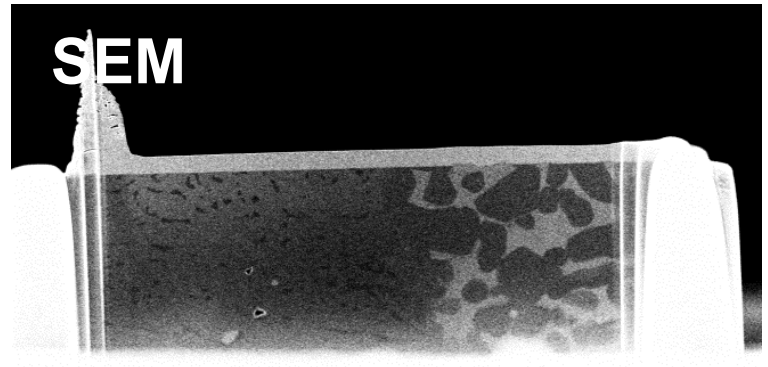

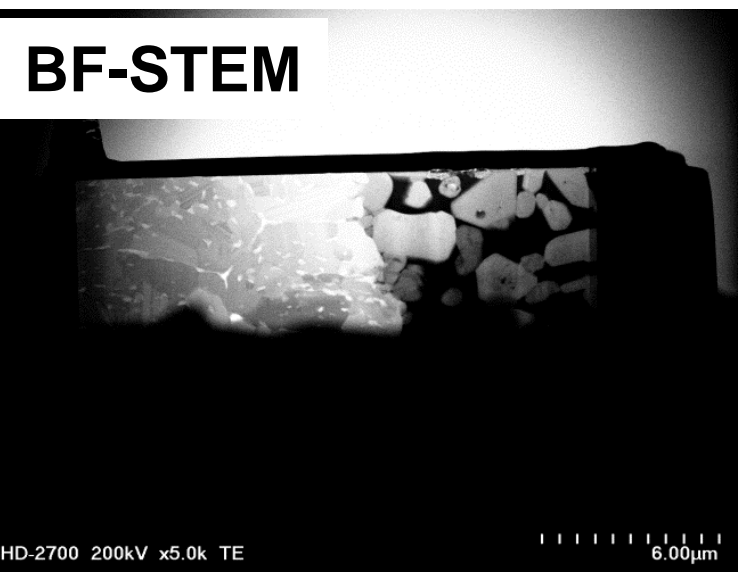

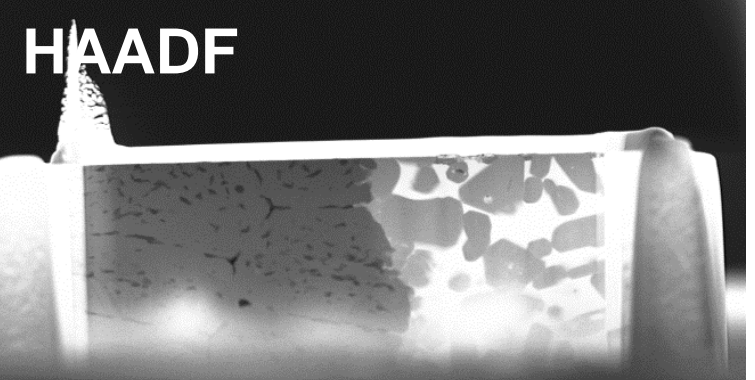




\section{HAADF}

SiC
(SA-THX)

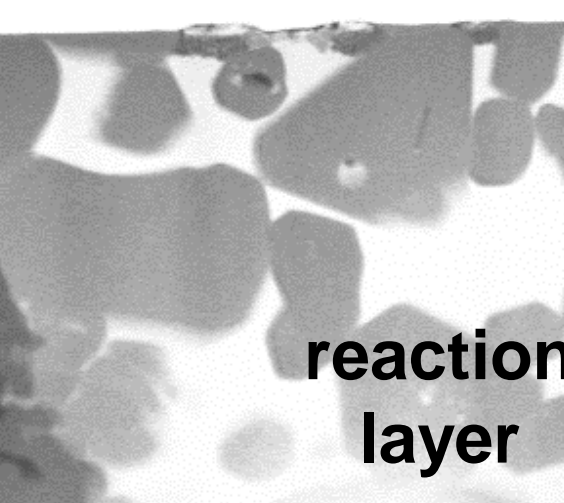

- Only one layer in the bonding area

- No diffusion toward the side of SiC

- The reaction layer is composed of some grains

and matrix around the grains. 


\section{Element Mapping obtained by STEM-EDS analysis}
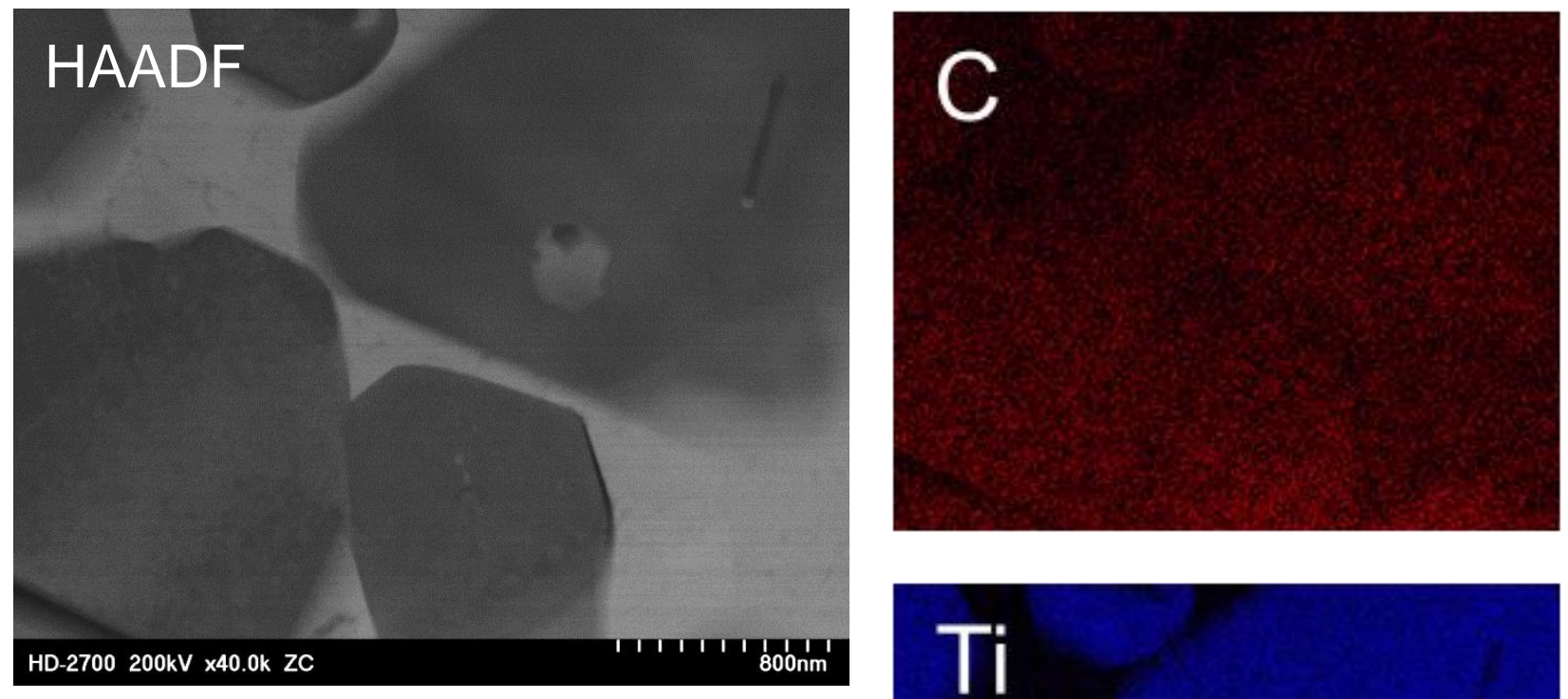

\section{Si}

\section{$\mathrm{Ti}$}

\section{$\mathrm{Cu}$}

* FIB mesh: Cu metal

\section{$\underline{\text { Cu-Si matrix }+ \text { precipitated TiC grains? }}$}




\section{TEM image and SAD patterns of Ti-C compound}

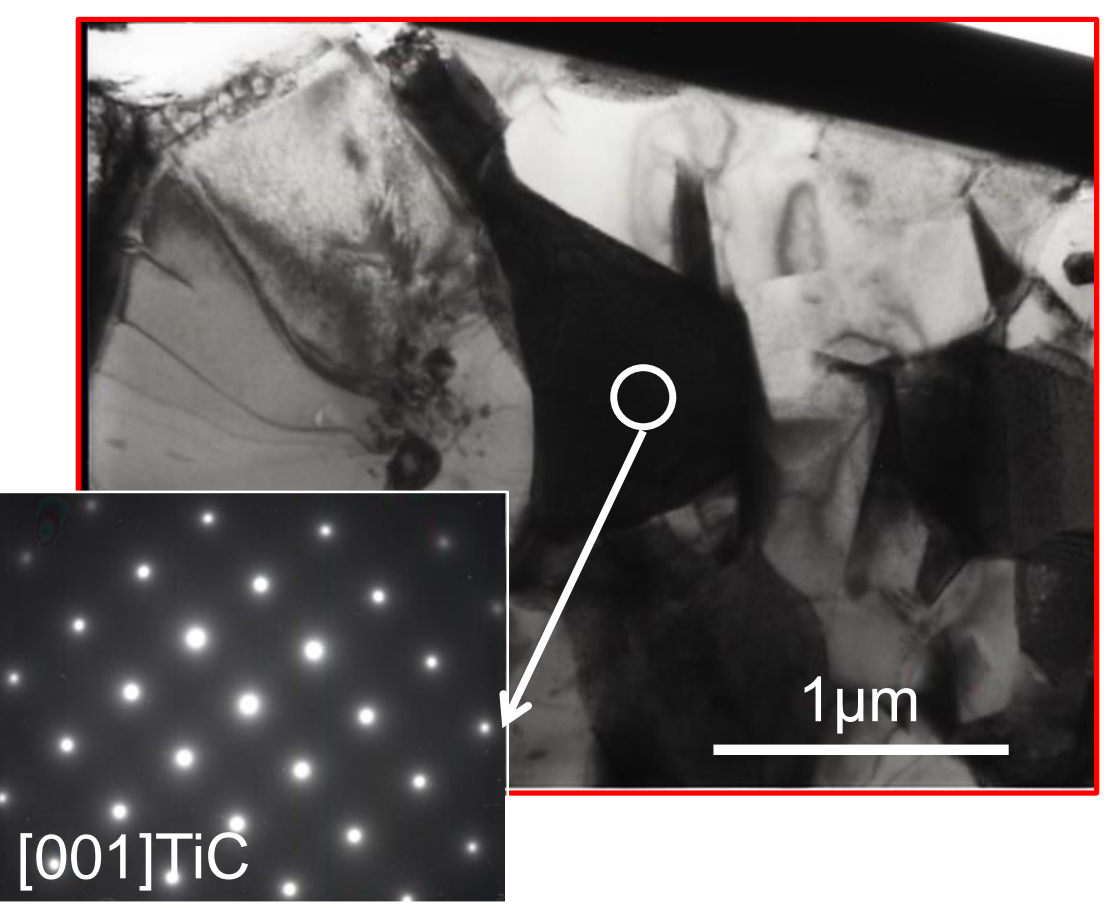

[001]TiC

$\mathrm{TiC}$

S.G.: Fm3m $\mathrm{NaCl}$-type

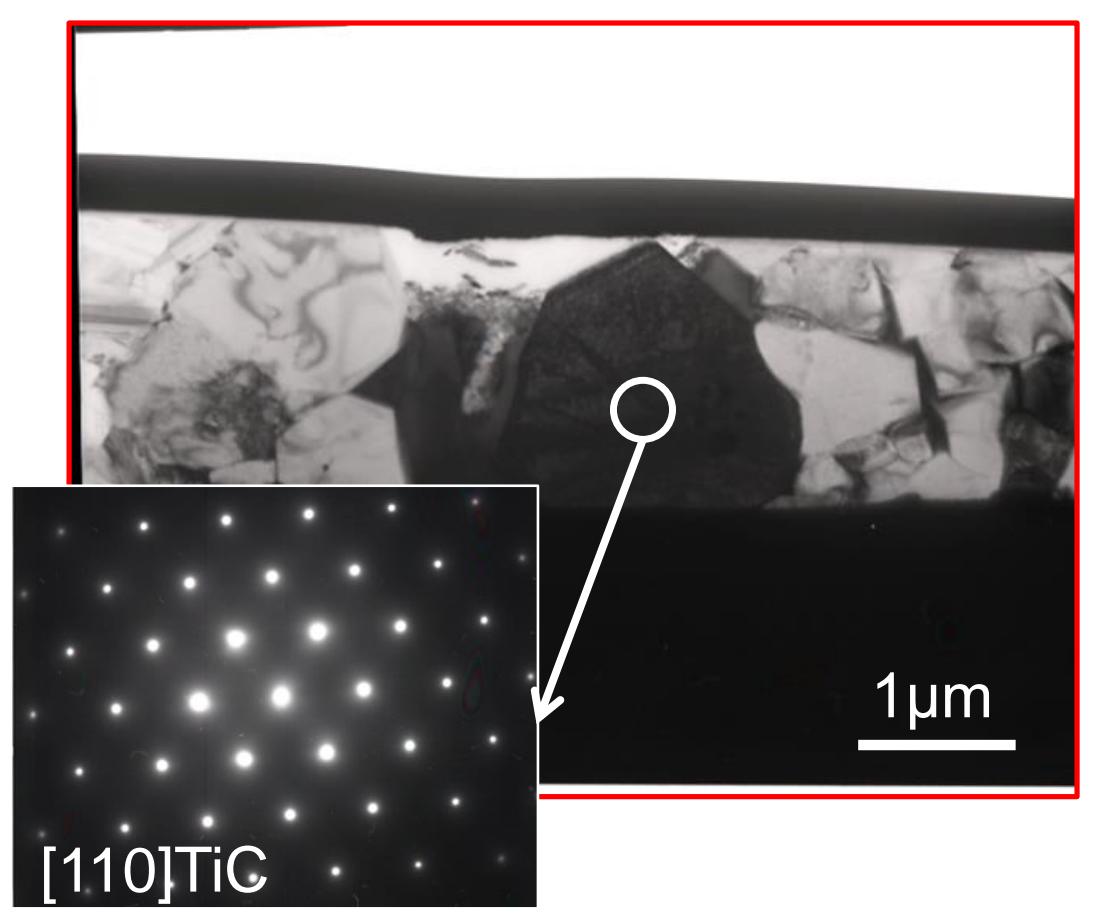

[110]TiC

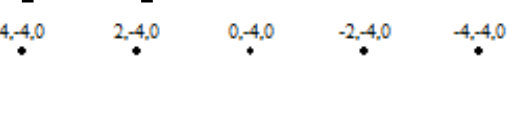

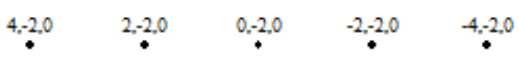

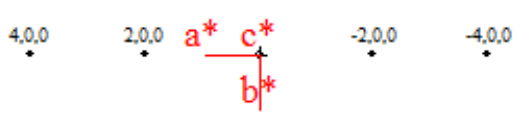

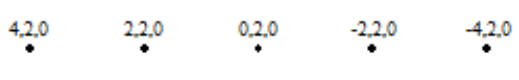

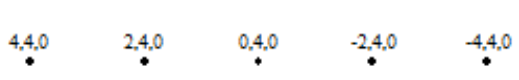

T Rosura 産技研 Let's Try with TRI!

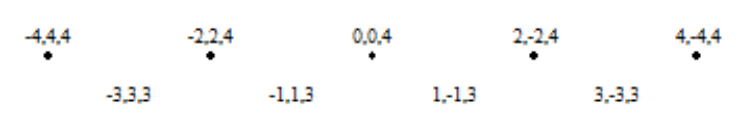

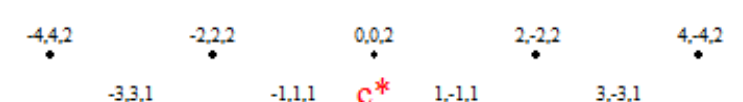

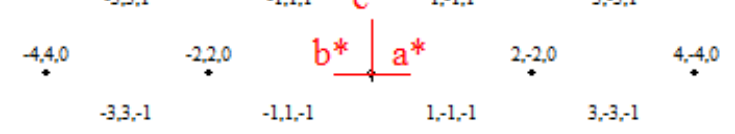

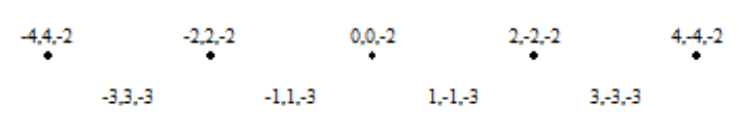




\section{TEM image and SAD patterns of Cu-Si compound}
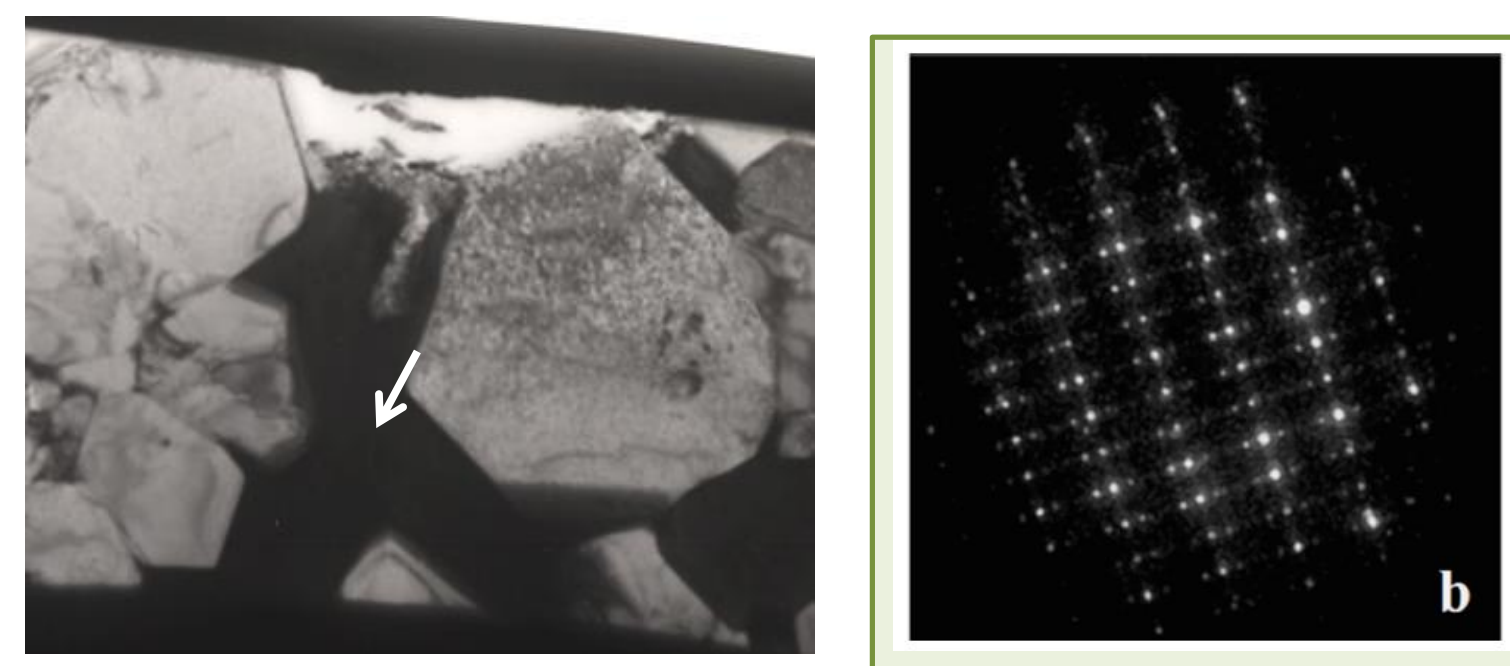

SAD pattern of $\underline{\mathrm{Cu}}_{3} \underline{\mathrm{Si}}$ :n"-phase

(RT phase of $\mathrm{Cu}_{3} \mathrm{Si}$ )

$/ /[001]$

4 times superstructure $/ /[111]$

M. Heuer, et. al., JAP 101, 123510 (2007)

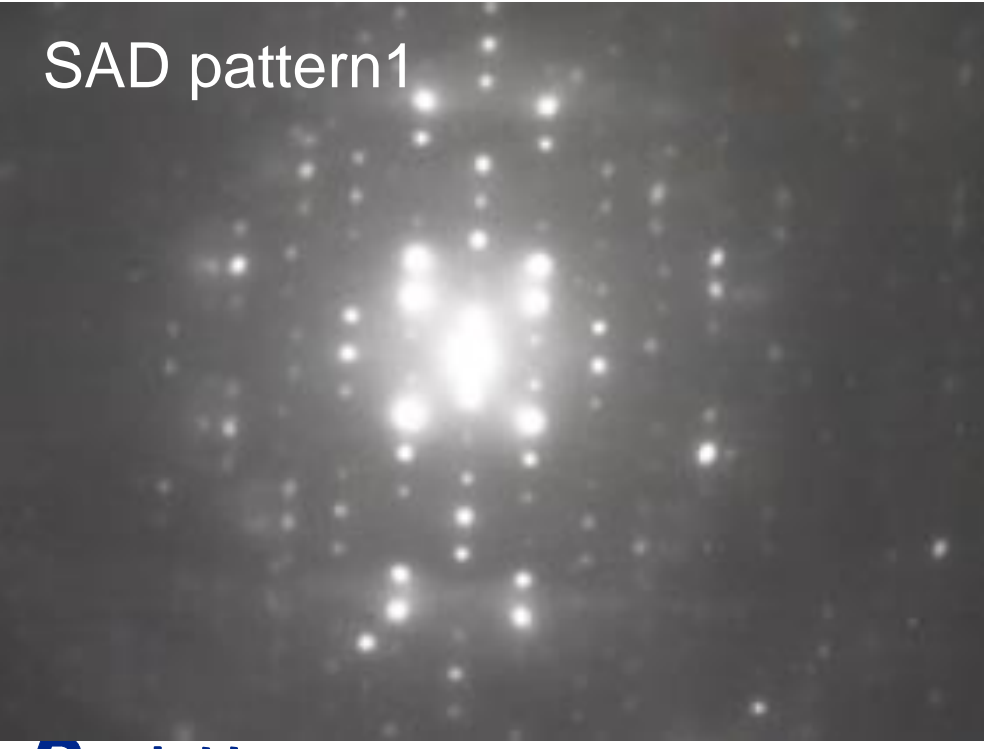

7.RI 産技研 Let's Try with TRI!

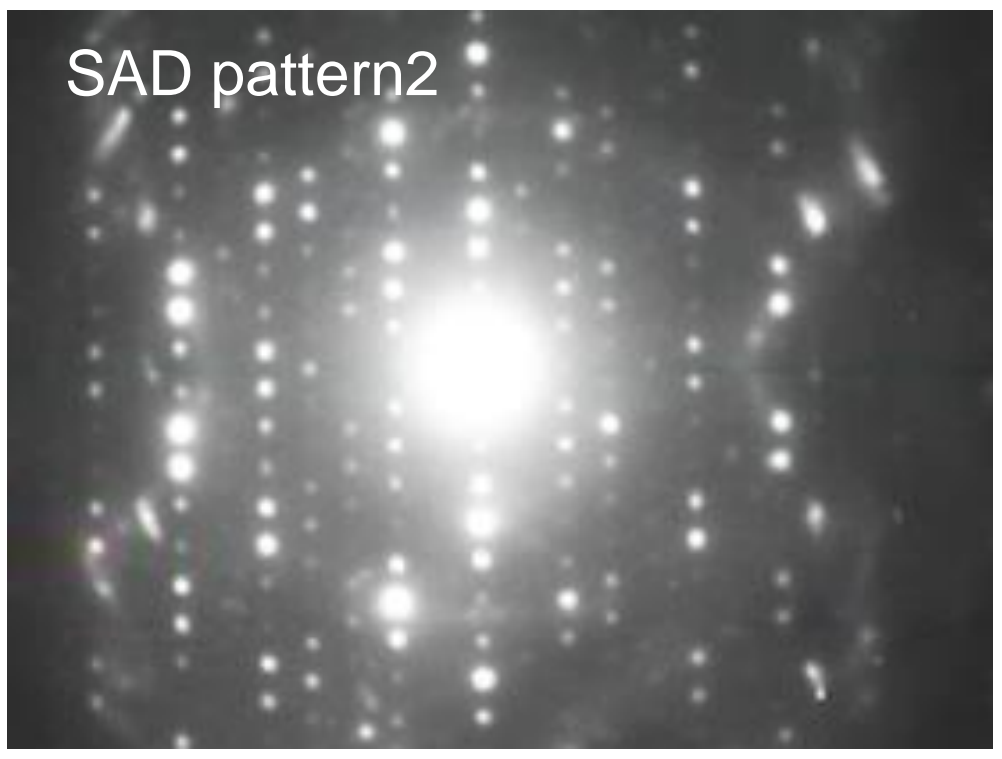




\section{TEM image and SAD patterns of Cu-Si compound}
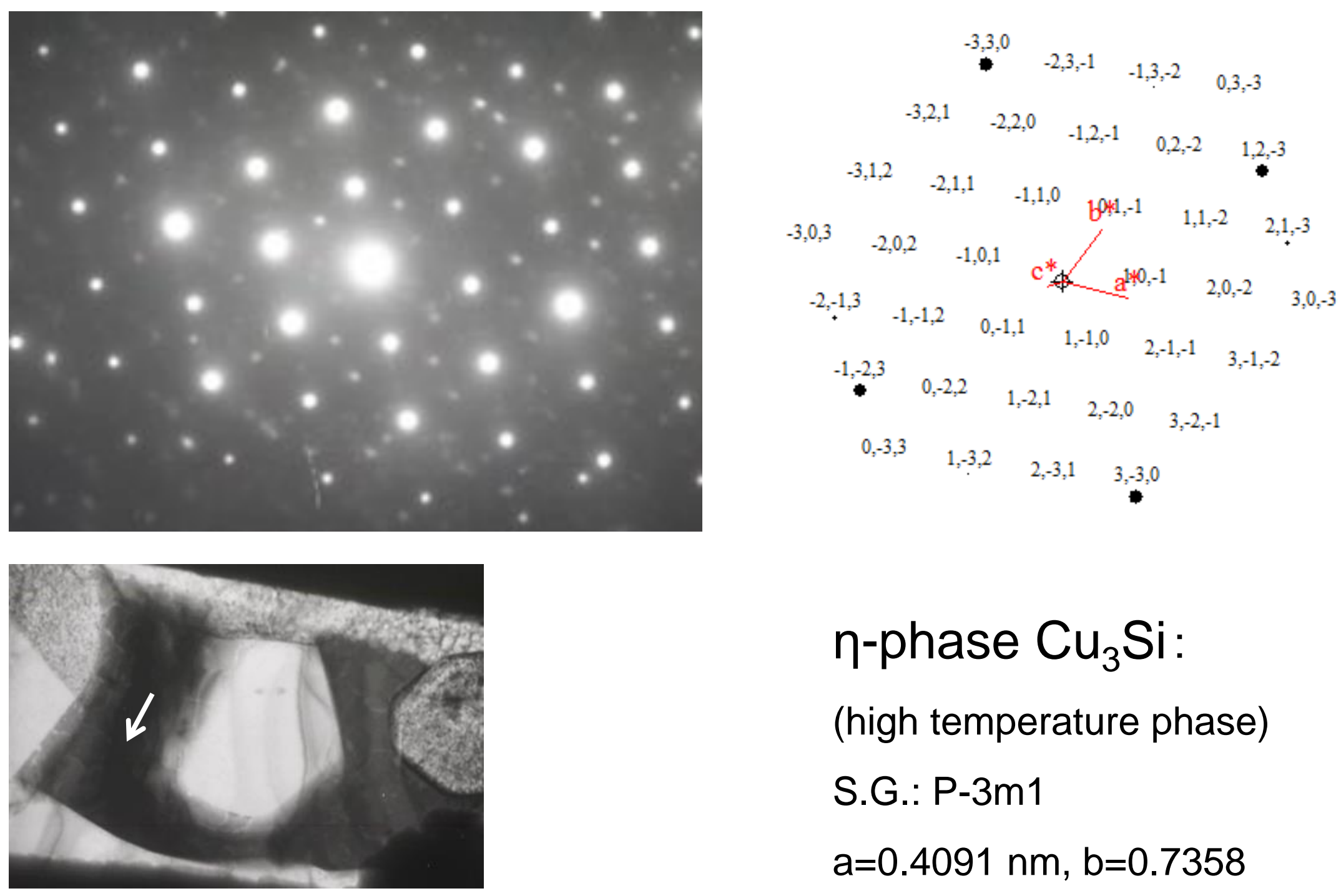

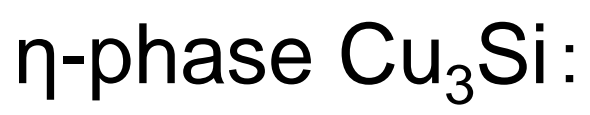

(high temperature phase)

S.G.: P-3m1

$$
a=0.4091 \mathrm{~nm}, \mathrm{~b}=0.7358
$$

7 Psara 産技研 Let's Try with TRI!

N. Mattern, et. al., HASYLAB ANNUAL REPORT (2001) 


\section{Consideration of the Results}

(1) RT (Before)

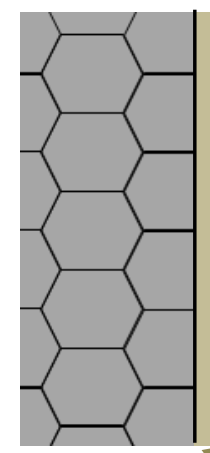

Ti-foil Cu-foil
(2) the top temperature

(2) $1200^{\circ} \mathrm{C}$

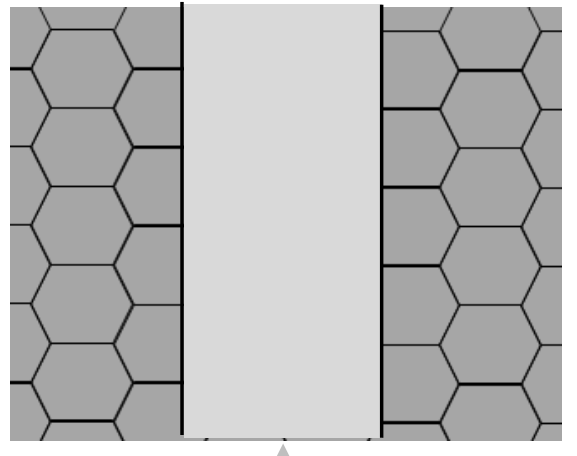

Liquid-state

(Cu-Ti-Si-C)
(3) cooling

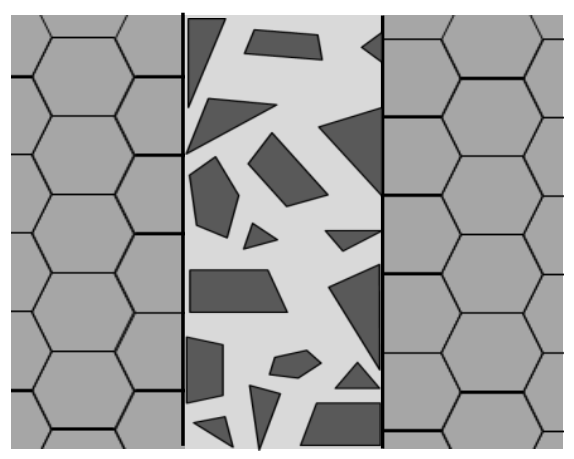

$\underline{\text { TiC crystallization }}$
(4) RT (After)

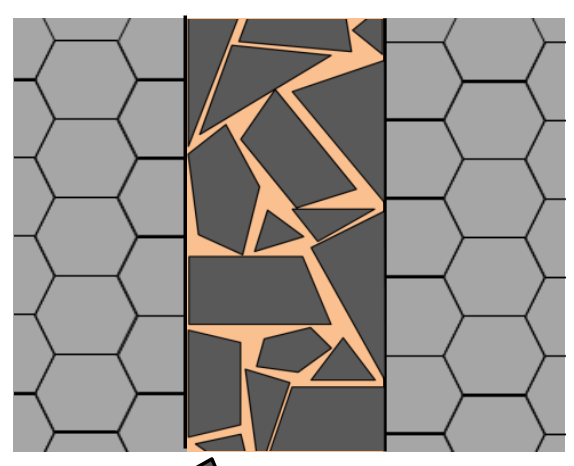

TiC

$\mathrm{Cu}-\mathrm{Si}$ compound

The bonding layer is composed of TiC precipitations in Cu-Si matrix.

Cu-Si matrix plays a role of the binder of TiC precipitations? 


\section{Consideration of the Results (CTE)}
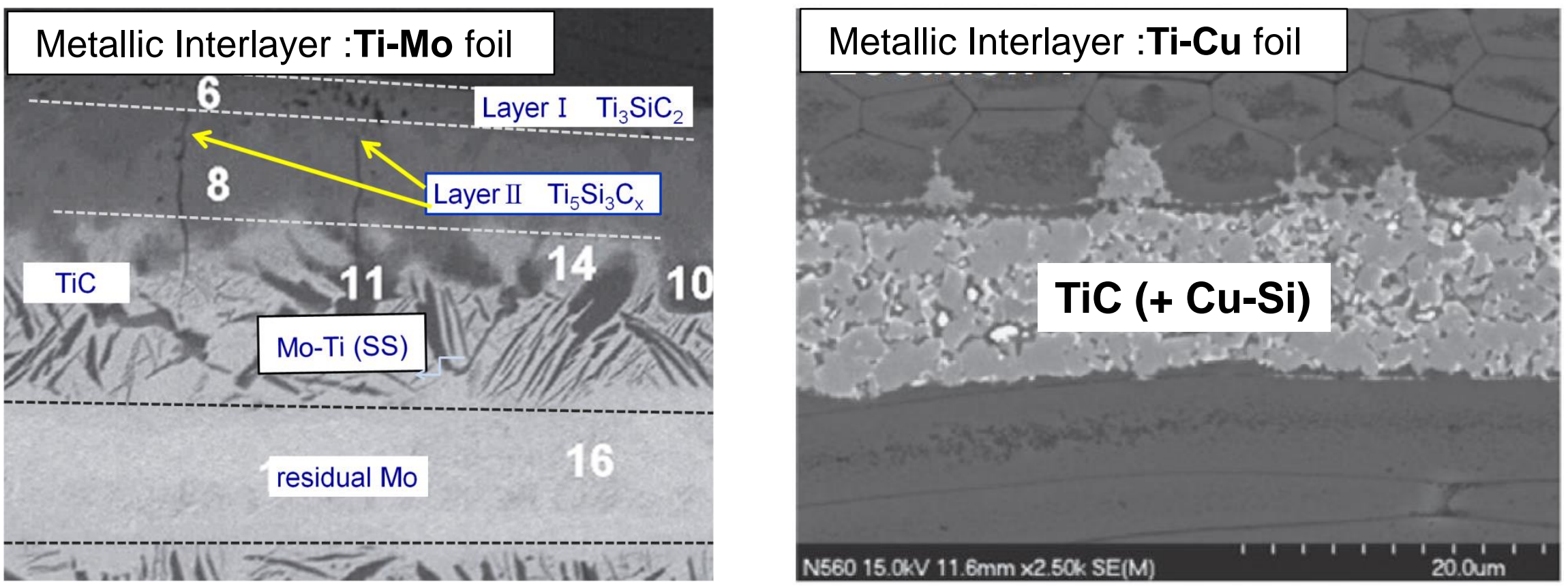

coefficient of thermal expansion (CTE; $\alpha$ )

\begin{tabular}{|c|c|c|c|c|c|c|c|c|c|}
\hline material & a-SiC & Mo & Ti & Cu & TiC & \multicolumn{2}{|c|}{ Ti3Si5 } & \multicolumn{2}{|c|}{ Ti3SiC2 } \\
\cline { 5 - 8 } & & & & & $\mathrm{a}$ & $\mathrm{a}$ & $\mathrm{c}$ \\
\hline $\begin{array}{c}\text { CTE } \alpha \\
\left(10^{-6} \mathrm{~K}^{-1}\right)\end{array}$ & 3.2 & 5.1 & 8.4 & 16.8 & 7.4 & 6.1 & 16.6 & 8.9 & 10 \\
\hline
\end{tabular}

Toske 産技研 Let's Try with TRI!

M.C. Halbig, et. al., Ceramics International41(2015)2140-2149 


\section{Summary}

$>1$. We picked up thin samples from the bonded area of diffusion bonded SA-THX by a FIB micro-sampling technique. The prepared thin samples were sufficiently thin and less-damaged, and allowed the detailed evaluation by TEM and STEM.

$>2$. The microstructure of diffusion bonded area was observed by STEM and TEM. The composition and crystal structures of the reaction compound were investigated by STEM-EDS and SAED method. The reaction layer of the diffusion bonding was composed of $\mathrm{TiC}$ precipitations in $\mathrm{Cu}-\mathrm{Si}$ compound matrix.

This work was supported by JSPS KAKENHI Grant Number JP16K06802. 